\title{
Capsaicin inhibits arginine kinase and exerts anti-Trypanosoma cruzi activity
}

Edward A. Valera-Vera ${ }^{1,2}$, Chantal Reigada ${ }^{1,2}$, Melisa Sayé ${ }^{1,2}$, Fabio A. Digirolamo ${ }^{1,2}$, Mariana R. Miranda ${ }^{1,2}$, and Claudio A. Pereira ${ }^{1,2,}$

${ }^{1}$ Universidad de Buenos Aires, Facultad de Medicina, Instituto de Investigaciones Médicas A. Lanari, Buenos Aires, Argentina.

2 Consejo Nacional de Investigaciones Científicas y Técnicas, Universidad de Buenos Aires, Instituto de Investigaciones Médicas (IDIM), Laboratorio de Parasitología Molecular, Buenos Aires, Argentina.

* Corresponding author: C. Pereira, IDIM, Av. Combatientes de Malvinas 3150, (1427) Buenos Aires, Argentina. Phone: 5411-52873920; FAX: 5411-45238947; Email address: cpereira@retina.ar 


\section{ABSTRACT}

Trypanosoma cruzi is the causative agent of Chagas disease, considered within the list of twenty neglected diseases according to the World Health Organization. There are only two therapeutic drugs for Chagas disease, both of them unsuitable for the chronic phase, therefore the development of new drugs is a priority.

T. cruzi arginine kinase (TcAK) is a promising drug target since it is absent in humans and it is involved in cellular stress responses. In a previous study from our laboratory, possible TcAK inhibitors were identified through computer simulations, resulting in the best-scoring compounds cyanidin derivatives and capsaicin. Considering these results, in this work we evaluate the effect of capsaicin on TcAK activity and its trypanocidal effect. Although capsaicin produced a weak inhibition on the recombinant TcAK activity $\left(\mathrm{IC}_{50} \approx 800 \mu \mathrm{M}\right)$, it had a strong trypanocidal effect on epimastigotes and trypomastigotes $\left(\mathrm{IC}_{50}=6.26 \mu \mathrm{M}\right.$ and $0.26 \mu \mathrm{M}$, respectively) being 20-fold more active on trypomastigotes than mammalian cells. Epimastigotes that overexpress TcAK were $37 \%$ more resistant to capsaicin than wild type parasites, suggesting that trypanocidal activity could be due, in part, to the enzyme inhibition. However, the difference between the concentrations at which the enzyme is inhibited and the parasite death is caused implies the presence of other targets. In this sense, the prohibitin-2 and calmodulin were identified as other possible capsaicin targets.

Capsaicin is a strong and selective trypanocidal agent active in nanomolar concentrations, with an $\mathrm{IC}_{50}$ 57-fold lower than benznidazole, the drug currently used for treating Chagas disease.

Keywords: Trypanosoma cruzi; Chagas disease; capsaicinoids; phenolic compounds; arginine kinase; capsaicin 


\section{INTRODUCTION}

Arginine kinase (AK, ATP:arginine phosphotransferase; EC 2.7.3.3) is an enzyme that catalyzes the reversible trans-phosphorylation between $\mathrm{N}$-phospho-L-arginine and ATP [1]. Our research group identified an AK-mediated phosphagen system in the protozoan parasites Trypanosoma cruzi and Trypanosoma brucei, the etiological agents of Chagas disease and human sleeping sickness, respectively [2-4]. In $T$. cruzi, the AK pathway is involved in cellular response mechanisms to nutritional stress, radical oxygen species, and trypanocidal drugs [5-7]. The loss of flagellar AK in $T$. brucei reduces swim velocity and affects the infection in tsetse flies [8], and total elimination of the AK activity by RNA interference (RNAi) decreased parasite growth more than $90 \%$, being lethal under oxidative stress conditions [9]. The presence of an arginine-based phosphagen and its biosynthetic pathway in these parasites, absent in the mammalian hosts, highlights the AK as a possible chemotherapy target against trypanosomiases such as Chagas disease (Pereira, 2014).

Chagas disease is a zoonosis that affects approximately 7 million people in Latin America, of which about $15 \%-30 \%$ develop the chronic clinical manifestations of the disease $[10,11]$. The epidemiological situation is aggravated if we consider the Chagas cases associated with migration towards non-endemic countries. Although early diagnosis and treatment are essential for a good prognosis, most of the infected people are detected late in the chronic phase. Currently there are only two available drugs for Chagas treatment; nifurtimox, introduced for clinical use in 1965, and benznidazole, introduced in 1971, both presenting severe side effects [12]. These trypanocidal treatments are less efficient in the chronic phase; for instance, benznidazole does not produce any improvement in the evolution of chronic chagas 
cardiomyopathy [13]. Although these drugs were discovered five decades ago, no new successful compounds have been developed to treat the disease, and those that reached clinical trials did not have the expected results [14].

The lack of new treatments is due in part to the little investment in research and development for this disease, raising the need for agile and low-cost strategies that allows the identification of new drugs and therapeutic alternatives. One of such strategies, the virtual screening, involves the use of computational tools to identify compounds with high chances of binding to a certain target [15]. In this sense, starting from the evidence of the green tea polyphenols catechin gallate and gallocatechin gallate inhibiting the $T$. cruzi AK (TcAK) $[16,17]$, computational tools have been used to predict different plant-derived phenolic products as potential inhibitors of AK. Computer simulations validated by in vitro assays postulated rutin, a flavonoid glycoside, as a non-competitive inhibitor of the locust AK, binding to the enzyme mainly by hydrophobic interactions [18]. In a previous work from our research group, a virtual screening campaign performed on a database of phenolic compounds identified resveratrol as a TcAK inhibitor, which showed in vitro antiparasite activity $\left(\mathrm{IC}_{50}=77 \mu \mathrm{M}\right)$ and a moderate inhibition of the enzyme $\left(\mathrm{IC}_{50}=325\right.$ $\mu \mathrm{M})$ [19]. In the same work, although not tested in vitro, the best-scored compounds from the virtual screening were three anthocyanidins, delphinidin, pelargonidin and cyanidin (polyphenolic plant pigments) and capsaicin [(E)-N-(4-hydroxy-3methoxybenzyl)-8-methyl-6-nonenamide], a phenolic antioxidant compound produced by peppers.

Capsaicin has been tested for the treatment of cancer, pain, obesity, dermatitis, diabetes, and other conditions [20]. However, little is known about the effect of this compound on trypanosomatid parasites. Capsaicin is a specific inhibitor of the 
complex I of the respiratory chain in many organisms, and was used as a tool to study cellular respiration in T. brucei [21] and Leishmania donovani [22], however, in T. cruzi the role of mitochondrial complex I in NADH oxidation is very limited or null $[23,24]$. In addition, capsaicin was evaluated against $L$. infantum in combination with meglumine antimoniate, obtaining a moderate antiparasitic effect [25]. Considering the in silico predictions of capsaicin as a TcAK inhibitor, its use in the treatment of many human pathologies, and its activity in other trypanosomatids, in this work, we tested the effect of this compound on the TcAK activity and the parasite survival.

\section{MATERIALS AND METHODS}

Parasites and cells. T. cruzi epimastigotes of the $Y$ strain were cultured at $28^{\circ} \mathrm{C}$ in BHT (brain-heart infusion-tryptose) medium supplemented with $10 \%$ fetal calf serum (FCS), $100 \mathrm{U} / \mathrm{ml}$ penicillin, $100 \mu \mathrm{g} / \mathrm{ml}$ streptomycin and $20 \mu \mathrm{g} / \mathrm{ml}$ hemin. Vero cells (African green monkey kidney) were cultured in MEM medium supplemented with $10 \%$ heat inactivated FCS, $0.15 \%(\mathrm{w} / \mathrm{v}) \mathrm{NaHCO}_{3}, 100 \mathrm{U} / \mathrm{ml}$ penicillin and $100 \mathrm{U} / \mathrm{ml}$ streptomycin at $37^{\circ} \mathrm{C}$ in $5 \% \mathrm{CO}_{2}$ atmosphere. Trypomastigotes were obtained from the extracellular medium of Vero infected cells as previously described [26].

Arginine kinase overexpressing parasites. The full-length $T$. cruzi arginine kinase gene (GeneBank ID: AAC82390.1) was cloned into the pTREX expression plasmid and transfected into T. cruzi epimastigotes as previously described [5]. Transfected parasites were cultured in BHT medium containing $500 \mu \mathrm{g} / \mathrm{ml}$ of $\mathrm{G} 418$.

Protein heterologous expression and purification. The full length TcAK gene was obtained by PCR amplification using genomic T. cruzi DNA as template and cloned into the pRSET-A expression vector (Invitrogen). Expression of recombinant AK was performed in E. coli strain BL21(DE3), cultivated in auto-induction medium (50 mM 
$\mathrm{Na}_{2} \mathrm{HPO}_{4}, 50 \mathrm{mM} \mathrm{KH}_{2} \mathrm{PO}_{4}, 10 \mathrm{mM} \mathrm{NH}_{4} \mathrm{Cl}, 5 \mathrm{mM} \mathrm{MgSO}_{4}, 4 \mathrm{mM} \mathrm{NaCl}, 0.2 \mathrm{mM} \mathrm{CaCl}$, $0.4 \%(\mathrm{v} / \mathrm{v})$ glycerol, $0.05 \%(\mathrm{w} / \mathrm{v})$ glucose, $0.05 \%(\mathrm{w} / \mathrm{v})$ lactose, $1 \%(\mathrm{w} / \mathrm{v})$ casein peptone, and $0.5 \%(\mathrm{w} / \mathrm{v})$ yeast extract) supplemented with $0.2 \mathrm{mg} / \mathrm{ml}$ ampicillin. As the expressed protein formed inclusion bodies, bacteria were washed, lysed by sonication, and the insoluble phase of the lysate was kept and washed three times with $50 \mathrm{mM}$ Tris- $\mathrm{HCl}$ buffer $\mathrm{pH}$ 8.0, denatured with $6 \mathrm{M}$ urea, and refolded by dilution 1:20 in $50 \mathrm{mM}$ Tris-HCl buffer $\mathrm{pH} 8.0,10 \%(\mathrm{v} / \mathrm{v})$ glycerol, 5\% (w/v) sucrose during $72 \mathrm{~h}$ at $4^{\circ} \mathrm{C}$. Purity of the protein was checked by SDS-PAGE followed by Coomassie blue staining.

Arginine kinase activity assays. TcAK activity was measured following the ADP production with coupled enzyme reactions as previously described [27]. Briefly, an 8 $\mu \mathrm{g}$ aliquot of recombinant TcAK was added to $100 \mu \mathrm{l}$ of the reaction mixture (100 mM Tris-HCl buffer $\mathrm{pH}$ 8.2, $1.5 \mathrm{mM}$ ATP, $1.5 \mathrm{mM}$ phosphoenolpyruvate, $1.5 \mathrm{mM}$ $\mathrm{MgCl}_{2}, 0.5 \mathrm{mM}$ DTT, $0.3 \mathrm{mM} \mathrm{NADH}, 10 \mathrm{mM}$ L-arginine, $5 \mathrm{U} / \mathrm{ml}$ pyruvate kinase and $5 \mathrm{U} / \mathrm{ml}$ lactate dehydrogenase) in a 96-well plates. The enzyme activity was determined measuring the decrease in absorbance at $340 \mathrm{~nm}$ due to the oxidation of $\mathrm{NADH}$.

Trypanocidal activity assays. Activity on epimastigotes was tested using $10^{7}$ cells $/ \mathrm{ml}$ epimastigote cultures in 24-well plates treated with $0-50 \mu \mathrm{M}$ of capsaicin during 72 h. Activity against trypomastigotes was evaluated using $10^{6}$ cells $/ \mathrm{ml}$ in $96-$ well plates incubated at $37^{\circ} \mathrm{C}$ for $24 \mathrm{~h}$ in the presence of $0-2.5 \mu \mathrm{M}$ of capsaicin. Cellular density was determined by cell counting in a Neubauer chamber.

Vero cell viability assay. Cytotoxicity against Vero cells was assayed by the crystal violet staining assay. The cells $\left(10^{4}\right.$ cells/well) were incubated at $37^{\circ} \mathrm{C}$ for $24 \mathrm{~h}$ in 96 well plates with $0-400 \mu \mathrm{M}$ of capsaicin. Then, cells were fixed for $15 \mathrm{~min}$ in 
methanol, and stained with $0.5 \%(\mathrm{w} / \mathrm{v})$ crystal violet. After washing with water and drying, the crystal violet staining the cells was solubilized with $200 \mu \mathrm{l}$ of methanol, and the absorbance was measured at $570 \mathrm{~nm}$.

Statistics and data analysis. $I_{50}$ values were obtained by non-linear regression of dose-response logistic functions, using GraphPad Prism 6.01. All experiments were performed in triplicate and results are presented as mean \pm standard deviation (SD). Alternative targets search Other possible molecular targets of capsaicin were searched using the following bioinformatics tools and databases: PASS (http://www.akosgmbh.de/pass/) [28], Similarity ensemble approach (SEA, http://sea.bkslab.org/)

[29],

Swiss

Target

Prediction

(http://www.swisstargetprediction.ch/) [30],

Target

Hunter

(https://www.cbligand.org/TargetHunter/)

KEGG

Compounds

database

(https://www.genome.jp/kegg/compound)

[32],

PubChem

(https://pubchem.ncbi.nlm.nih.gov/) and DrugBank (https://www.drugbank.ca/). 


\section{RESULTS}

Inhibition of TcAK. In order to determine if capsaicin can act as an TcAK inhibitor, enzyme activity assays were performed using a concentration range between $0-2$ $\mathrm{mM}$ capsaicin in the presence of saturating concentrations of the substrates Larginine and ATP. As Fig. 1A shows, TcAK activity in presence of capsaicin decreased in a dose-dependent manner, reaching 50\% inhibition only at high concentrations of capsaicin of approximately $0.8 \mathrm{mM}$.

Trypanocidal effect on epimastigotes. To evaluate the effect of capsaicin on the replication of the insect-infecting stage of $T$. cruzi, epimastigote cells were exposed to the compound during $72 \mathrm{~h}$ in a concentration range of $0-50 \mu \mathrm{M}$. Results showed that capsaicin inhibited the epimastigotes growth with an $\mathrm{IC}_{50}$ (concentration of compound which gave $50 \%$ relative number of parasites compared to the untreated control) of $6.26( \pm 0.41) \mu \mathrm{M}$ (Fig. 1B).

Considering that $\mathrm{AK}$ is an important component of stress responses in $T$. cruzi, we evaluated the role of this enzyme in the mechanism of action of the capsaicinmediated trypanocidal effect. Thus, we compared the $\mathrm{IC}_{50}$ calculated for wild type epimastigotes and transgenic parasites overexpressing AK. Remarkably, epimastigotes overexpressing AK were 37\% more resistant to capsaicin than control parasites, with an $\mathrm{IC}_{50}$ of $8.56( \pm 0.81) \mu \mathrm{M}(\mathrm{Fig} .1 \mathrm{~B})$.

As the concentrations of capsaicin inhibiting the enzyme are two orders of magnitude higher than the concentrations killing the parasite, the results suggest that the effect on epimastigote viability is not a direct consequence of TcAK inhibition, but the higher resistance of the overexpressing cells indicates that this pathway could be involved in the response to the capsaicin-mediated trypanocidal effect. 
Trypanocidal effect on trypomastigotes. The trypanocidal effect of capsaicin was tested in bloodstream trypomastigotes, a therapeutically relevant stage of the $T$. cruzi life cycle. Interestingly, when trypomastigotes were exposed to capsaicin concentrations up to $2.5 \mu \mathrm{M}$, the calculated $\mathrm{IC}_{50}$ was $0.26( \pm 0.02) \mu \mathrm{M}$ demonstrating that trypomastigotes are more sensitive to capsaicin than epimastigotes (Fig. 2A). Moreover, the compound presented an $\mathrm{IC}_{50}$ 57-fold lower than the drug benznidazole, being $14.9( \pm 1.5) \mu \mathrm{M}$ when tested in similar conditions [33]. Finally, the cytotoxicity of capsaicin was assayed using the mammalian Vero cell line (Fig. 2B) and the calculated $\mathrm{IC}_{50}$ was $5.26( \pm 0.44) \mu \mathrm{M}$, representing a selectivity index $\left(\mathrm{IC}_{50}\right.$ Vero / IC 50 trypomastigotes) of 20.23.

Prediction of other capsaicin targets in T. cruzi. As previously mentioned, considering the differences between the $\mathrm{IC}_{50}$ obtained for $\mathrm{AK}$ inhibition and the trypanocidal activity on epimastigotes and trypomastigotes (about 100 and 3,000-fold lower, respectively) it can be hypothesized that other targets of capsaicin, besides TcAK, are present in T. cruzi. Thus, applying seven in silico "target fishing" tools and databases two protein candidates, that could interact with capsaicin, were obtained. A search in the DrugBank database provided information about the binding of capsaicin to the human prohibitin-2 (PHB2), a protein involved in the maintenance of mitochondrial morphology and the control of apoptosis. This interaction induces PHB2 translocation from the inner mitochondrial membrane, where it is normally localized, to the nucleus, triggering apoptosis at multiple levels [34]. Regarding trypanosomatids, in T. brucei PHB1 and PHB2 are located in the mitochondrion and seem to be essential for mitochondrial translation, to maintain the flagellar morphology and are also involved in apoptosis $[35,36]$. It was postulated in L. major 
that PHB1 and PHB2 protect membranes and DNA against superoxide ions in oxidative stress conditions, increasing the survival capacity of the parasites [37].

A search in the PubChem database showed that capsaicin binds to human calmodulin at nanomolar concentrations, competitively inhibiting its interaction with TRPV1, a ionotropic receptor involved in pain stimulus [38]. Interestingly, there is a report of another flavonoid (5-methoxy-6,7-methylenedioxyflavone) affecting the $\mathrm{Ca}^{2+}$ regulation in trypanosomatids [39]. Other bioinformatics tools used (see "Materials and Methods") did not give any hits or they were not applicable to trypanosomatids.

All this evidence highlights PHB2 and calmodulin as possible targets for capsaicin in T. cruzi. 


\section{DISCUSSION}

Phenolic compounds derived from natural products have been intensively studied to treat a wide variety of conditions, including cancer, inflammation, pain, ageing, cardiomyopathy, hepatotoxicity, obesity, viral and bacterial infections, dermatitis, among other pathologies [40].

The enzyme arginine kinase, completely absent in mammals, is involved in stress responses through the maintenance of the cell energy homeostasis. The essentiality of this enzyme was demonstrated by RNAi in $T$. brucei and, by different pharmacological approaches, in $T$. cruzi $[9,17]$. There are two identified chemical groups of TcAK inhibitors: arginine structural analogs and plant-produced phenolic compounds $[19,27]$. In a previous work we performed a virtual screening campaign searching potential $T$. cruzi AK inhibitors in a database of antioxidant phenolic compounds, where resveratrol was selected for further characterization [19]. Although capsaicin scored higher than resveratrol as a possible TcAK inhibitor in the virtual screening $(-8.56$ and $-6.96 \mathrm{kcal} / \mathrm{mol}$, respectively), the experimental validation showed that capsaicin achieved $50 \%$ enzyme inhibition at concentrations 2.5 -fold higher than the reported for resveratrol. Regarding the trypanocidal activity, capsaicin performed better than resveratrol, with potency 15 -fold higher in epimastigotes and 300-fold in trypomastigotes. According to the results herein obtained, capsaicin acts as a moderate inhibitor of T. cruzi AK. However, the trypanocidal potency of this compound is 2 to 3 orders of magnitude higher than the TcAK inhibition, suggesting that capsaicin has other targets besides TcAK. In addition, TcAK overexpression increases $\mathrm{IC}_{50}$ of capsaicin suggesting that although it is not the main target, it is probably involved in resistance mechanisms to capsaicin-mediated cytotoxicity. 
Searching in different compound databases, two probable targets were identified, the protein PHB2, a multifunctional protein involved in apoptosis and oxidative stress protection, and calmodulin, a calcium-binding messenger protein expressed in all eukaryotic cells. The binding of capsaicin to human PHB2 and calmodulin were previously demonstrated [34,38] and both proteins are present in trypanosomatid organisms. Although other targets have not been determined with certainty, there is convincing evidence of the multitarget nature of capsaicin trypanocidal activity.

Capsaicin can be considered a potent and selective anti-T. cruzi agent since it is active in nanomolar concentrations, 57-fold more potent than benznidazole [41], the drug currently used to treat Chagas disease. In addition, orally administered free capsaicin suspension and capsaicin loaded liposomes in rats at a single dose of 90 $\mathrm{mg} \cdot \mathrm{kg}^{-1}$ reach a plasma concentration of about $2.6 \mu \mathrm{M}$ that is progressively reduced to $50 \%$ at $2 \mathrm{~h}$ or $24 \mathrm{~h}$ for free or liposome formulation of capsaicin, respectively [42]. These data are particularly relevant since the calculated $I_{50}$ for $T$. cruzi trypomastigotes is 10 -fold lower than the maximum concentration achieved in plasma, suggesting that capsaicin could be a good candidate for an oral treatment of trypanosomiasis.

Finally, other advantages of capsaicin to be used as a trypanocidal drug include that can be administered orally (free or in liposomes), it is very stable at room temperature, easily available at a low market price (about about USD 270 per $\mathrm{kg}$ ) and its pharmacological properties are widely known. 


\section{Acknowledgements}

This work was supported by Consejo Nacional de Investigaciones Científicas y Técnicas, Agencia Nacional de Promoción Científica y Tecnológica (FONCyT PICT 2015-0539, 2018-1801 and 2018-1871). The research leading to these results has, in part, received funding from UK Research and Innovation via the Global Challenges Research Fund under grant agreement 'A Global Network for Neglected Tropical Diseases' grant number MR/P027989/1. CAP and MRM are members of the career of the scientific investigator; EVV and CR are research fellows from CONICET; FAD is a scientific technician from CONICET, and MS is PDRA from the A Global Network for Neglected Tropical Diseases. 


\section{References}

[1] W.R. Ellington, Evolution and physiological roles of phosphagen systems, Annu Rev Physiol 63 (2001) 289-325. 10.1146/annurev.physiol.63.1.289.

[2] C.A. Pereira, G.D. Alonso, H.N. Torres, M.M. Flawia, Arginine kinase: a common feature for management of energy reserves in African and American flagellated trypanosomatids, J Eukaryot Microbiol 49 (2002) 82-85.

[3] C.A. Pereira, G.D. Alonso, M.C. Paveto, A. Iribarren, M.L. Cabanas, H.N. Torres, M.M. Flawia, Trypanosoma cruzi arginine kinase characterization and cloning. A novel energetic pathway in protozoan parasites, J Biol Chem 275 (2000) 1495-1501.

[4] C.A. Pereira, G.D. Alonso, M.C. Paveto, M.M. Flawia, H.N. Torres, L-arginine uptake and L-phosphoarginine synthesis in Trypanosoma cruzi, J Eukaryot Microbiol 46 (1999) 566-570.

[5] C.A. Pereira, G.D. Alonso, S. Ivaldi, A.M. Silber, M.J. Alves, H.N. Torres, M.M. Flawia, Arginine kinase overexpression improves Trypanosoma cruzi survival capability, FEBS Lett 554 (2003) 201-205. S0014579303011712 [pii].

[6] C.A. Pereira, G.D. Alonso, S. Ivaldi, A. Silber, M.J. Alves, L.A. Bouvier, M.M. Flawia, H.N. Torres, Arginine metabolism in Trypanosoma cruzi is coupled to parasite stage and replication, FEBS Lett 526 (2002) 111-114. S0014579302031575 [pii].

[7] M.R. Miranda, G.E. Canepa, L.A. Bouvier, C.A. Pereira, Trypanosoma cruzi: Oxidative stress induces arginine kinase expression, Exp Parasitol 114 (2006) 341344. S0014-4894(06)00099-3 [pii] 
10.1016/j.exppara.2006.04.004.

[8] C.P. Ooi, B. Rotureau, S. Gribaldo, C. Georgikou, D. Julkowska, T. Blisnick, S. Perrot, I. Subota, P. Bastin, The Flagellar Arginine Kinase in Trypanosoma brucei Is Important for Infection in Tsetse Flies, PLoS One 10 (2015) e0133676. 10.1371/journal.pone.0133676.

[9] F. Voncken, F. Gao, C. Wadforth, M. Harley, C. Colasante, The phosphoarginine energy-buffering system of trypanosoma brucei involves multiple arginine kinase isoforms with different subcellular locations, PLoS One 8 (2013) e65908. 10.1371/journal.pone.0065908

PONE-D-12-35515 [pii].

[10] L.E. Echeverria, C.A. Morillo, American Trypanosomiasis (Chagas Disease), Infect Dis Clin North Am 33 (2019) 119-134. 10.1016/j.idc.2018.10.015.

[11] C. Chagas, Nova Tripanosomiaze Humana: Estudos sobre amorfolojia e o ciclo evolutivo do Schizotrypanum cruzi n. gen., n. sp., ajente etiolojico de uma nova entidade mórbida do homem. , Mem. Inst. Oswaldo Cruz 1 (1909) 159 - 218.

[12] P.A. Sales Junior, I. Molina, S.M. Fonseca Murta, A. Sanchez-Montalva, F. Salvador, R. Correa-Oliveira, C.M. Carneiro, Experimental and Clinical Treatment of Chagas Disease: A Review, Am J Trop Med Hyg 97 (2017) 1289-1303. 10.4269/ajtmh.16-0761.

[13] J.A. Marin-Neto, A. Rassi, Jr., A. Avezum, Jr., A.C. Mattos, A. Rassi, C.A. Morillo, S. Sosa-Estani, S. Yusuf, The BENEFIT trial: testing the hypothesis that trypanocidal therapy is beneficial for patients with chronic Chagas heart disease, 
Mem Inst Oswaldo Cruz 104 Suppl 1 (2009) 319-324. S0074-02762009000900042 [pii].

[14] K. Salomao, R.F. Menna-Barreto, S.L. de Castro, Stairway to Heaven or Hell? Perspectives and Limitations of Chagas Disease Chemotherapy, Curr Top Med Chem 16 (2016) 2266-2289. 10.2174/1568026616666160413125049.

[15] C.A. Pereira, M. Saye, C. Reigada, A.M. Silber, G.R. Labadie, M.R. Miranda, E. Valera-Vera, Computational approaches for drug discovery against trypanosomatidcaused diseases, Parasitology 147 (2020) 611-633. 10.1017/S0031182020000207.

[16] M.C. Guida, M.I. Esteva, A. Camino, M.M. Flawia, H.N. Torres, C. Paveto, Trypanosoma cruzi: in vitro and in vivo antiproliferative effects of epigallocatechin gallate (EGCg), Exp Parasitol 117 (2007) 188-194. 10.1016/j.exppara.2007.04.015.

[17] C. Paveto, M.C. Guida, M.I. Esteva, V. Martino, J. Coussio, M.M. Flawia, H.N. Torres, Anti-Trypanosoma cruzi activity of green tea (Camellia sinensis) catechins, Antimicrob Agents Chemother 48 (2004) 69-74.

[18] X.Q. Wu, W.J. Zhu, Z.R. Lu, Y. Xia, J.M. Yang, F. Zou, X.Y. Wang, The effect of rutin on arginine kinase: inhibition kinetics and thermodynamics merging with docking simulation, Int J Biol Macromol 44 (2009) 149-155. 10.1016/j.jjbiomac.2008.11.007

S0141-8130(08)00272-9 [pii].

[19] E.A. Valera Vera, M. Saye, C. Reigada, F.S. Damasceno, A.M. Silber, M.R. Miranda, C.A. Pereira, Resveratrol inhibits Trypanosoma cruzi arginine kinase and 
exerts a trypanocidal activity, Int J Biol Macromol (2016). S0141-8130(16)30238-0 [pii]

10.1016/j.ijbiomac.2016.03.014.

[20] A.M. Chapa-Oliver, L. Mejia-Teniente, Capsaicin: From Plants to a CancerSuppressing Agent, Molecules 21 (2016). 10.3390/molecules21080931.

[21] J. Fang, Y. Wang, D.S. Beattie, Isolation and characterization of complex I, rotenone-sensitive $\mathrm{NADH}$ : ubiquinone oxidoreductase, from the procyclic forms of Trypanosoma brucei, Eur J Biochem 268 (2001) 3075-3082. 10.1046/j.14321327.2001.02205.x.

[22] T. Bera, K. Lakshman, D. Ghanteswari, S. Pal, D. Sudhahar, M.N. Islam, N.R. Bhuyan, P. Das, Characterization of the redox components of transplasma membrane electron transport system from Leishmania donovani promastigotes, Biochim Biophys Acta 1725 (2005) 314-326. 10.1016/j.bbagen.2005.05.024.

[23] J.C. Carranza, A.J. Kowaltowski, M.A. Mendonca, T.C. de Oliveira, F.R. Gadelha, B. Zingales, Mitochondrial bioenergetics and redox state are unaltered in Trypanosoma cruzi isolates with compromised mitochondrial complex I subunit genes, J Bioenerg Biomembr 41 (2009) 299-308. 10.1007/s10863-009-9228-4.

[24] L. Berna, M.L. Chiribao, G. Greif, M. Rodriguez, F. Alvarez-Valin, C. Robello, Transcriptomic analysis reveals metabolic switches and surface remodeling as key processes for stage transition in Trypanosoma cruzi, PeerJ 5 (2017) e3017. 10.7717/peerj.3017. 
[25] F.M. Vieira-Araujo, F.C. Macedo Rondon, I.G. Pinto Vieira, F.N. Pereira Mendes, J.C. Carneiro de Freitas, S. Maia de Morais, Sinergism between alkaloids piperine and capsaicin with meglumine antimoniate against Leishmania infantum, Exp Parasitol 188 (2018) 79-82. 10.1016/j.exppara.2018.04.001.

[26] N.W. Andrews, W. Colli, Adhesion and interiorization of Trypanosoma cruzi in mammalian cells, J Protozool 29 (1982) 264-269.

[27] C.A. Pereira, G.D. Alonso, S. Ivaldi, L.A. Bouvier, H.N. Torres, M.M. Flawia, Screening of substrate analogs as potential enzyme inhibitors for the arginine kinase of Trypanosoma cruzi, J Eukaryot Microbiol 50 (2003) 132-134.

[28] A.V. Stepanchikova, A.A. Lagunin, D.A. Filimonov, V.V. Poroikov, Prediction of biological activity spectra for substances: evaluation on the diverse sets of drug-like structures, Curr Med Chem 10 (2003) 225-233. 10.2174/0929867033368510.

[29] M.J. Keiser, B.L. Roth, B.N. Armbruster, P. Ernsberger, J.J. Irwin, B.K. Shoichet, Relating protein pharmacology by ligand chemistry, Nat Biotechnol 25 (2007) 197206. $10.1038 /$ nbt1284.

[30] A. Daina, O. Michielin, V. Zoete, SwissTargetPrediction: updated data and new features for efficient prediction of protein targets of small molecules, Nucleic Acids Res 47 (2019) W357-W364. 10.1093/nar/gkz382.

[31] L. Wang, C. Ma, P. Wipf, H. Liu, W. Su, X.Q. Xie, TargetHunter: an in silico target identification tool for predicting therapeutic potential of small organic molecules based on chemogenomic database, The AAPS journal 15 (2013) 395406. $10.1208 / \mathrm{s} 12248-012-9449-\mathrm{z}$. 
[32] M. Kanehisa, S. Goto, KEGG: kyoto encyclopedia of genes and genomes, Nucleic Acids Res 28 (2000) 27-30. 10.1093/nar/28.1.27.

[33] M. Saye, L. Gauna, E. Valera-Vera, C. Reigada, M.R. Miranda, C.A. Pereira, Crystal violet structural analogues identified by in silico drug repositioning present anti-Trypanosoma cruzi activity through inhibition of proline transporter TcAAAP069, PLoS Negl Trop Dis 14 (2020) e0007481. 10.1371/journal.pntd.0007481.

[34] C. Kuramori, M. Azuma, K. Kume, Y. Kaneko, A. Inoue, Y. Yamaguchi, Y. Kabe, T. Hosoya, M. Kizaki, M. Suematsu, H. Handa, Capsaicin binds to prohibitin 2 and displaces it from the mitochondria to the nucleus, Biochem Biophys Res Commun 379 (2009) 519-525. 10.1016/j.bbrc.2008.12.103.

[35] J. Tyc, D. Faktorova, E. Kriegova, M. Jirku, Z. Vavrova, D.A. Maslov, J. Lukes, Probing for primary functions of prohibitin in Trypanosoma brucei, Int J Parasitol 40 (2010) 73-83. 10.1016/j.ijpara.2009.07.008.

[36] S.C. Welburn, N.B. Murphy, Prohibitin and RACK homologues are up-regulated in trypanosomes induced to undergo apoptosis and in naturally occurring terminally differentiated forms, Cell Death Differ 5 (1998) 615-622. 10.1038/sj.cdd.4400393.

[37] T. Cruz-Bustos, A.K. Ibarrola-Vannucci, I. Diaz-Lozano, J.L. Ramirez, A. Osuna, Characterization and functionality of two members of the SPFH protein superfamily, prohibitin 1 and 2 in Leishmania major, Parasit Vectors 11 (2018) 622. 10.1186/s13071-018-3195-8.

[38] A. Hetenyi, L. Nemeth, E. Weber, G. Szakonyi, Z. Winter, K. Josvay, E. Bartus, Z. Olah, T.A. Martinek, Competitive inhibition of TRPV1-calmodulin interaction by vanilloids, FEBS Lett 590 (2016) 2768-2775. 10.1002/1873-3468.12267. 
[39] Y. De-Gouveia, V. Hernández-Rodríguez, J. Rodríguez-Durán, A. Suárez, G. Benaim, Effect of a methylenedioxy-flavonoid isolated from Iresine diffusa on the cellular viability of Leishmania mexicana and the intracellular homeostasis of $\mathrm{Ca2+}$, Investigación Clínica 58 (2017) 334-351.

[40] M.S. Swallah, H. Sun, R. Affoh, H. Fu, H. Yu, Antioxidant Potential Overviews of Secondary Metabolites (Polyphenols) in Fruits, International journal of food science 2020 (2020) 9081686. 10.1155/2020/9081686.

[41] M. Moreno, A. D'Avila D, M.N. Silva, L.M. Galvao, A.M. Macedo, E. Chiari, E.D. Gontijo, B. Zingales, Trypanosoma cruzi benznidazole susceptibility in vitro does not predict the therapeutic outcome of human Chagas disease, Mem Inst Oswaldo Cruz 105 (2010) 918-924. 10.1590/s0074-02762010000700014.

[42] Y. Zhu, M. Wang, J. Zhang, W. Peng, C.K. Firempong, W. Deng, Q. Wang, S. Wang, F. Shi, J. Yu, X. Xu, W. Zhang, Improved oral bioavailability of capsaicin via liposomal nanoformulation: preparation, in vitro drug release and pharmacokinetics in rats, Arch Pharm Res 38 (2015) 512-521. 10.1007/s12272-014-0481-7. 


\section{Figure Legends}

Figure 1. Effect of capsaicin on TcAK activity and epimastigotes viability. A) TcAK activity was measured by coupled enzymes method in presence of $0-2 \mathrm{mM}$ capsaicin, under saturating concentration of arginine and ATP, using a recombinant purified enzyme as described under "Materials and Methods". Activity was expressed as percentage of the control without capsaicin. B) Trypanocidal effect of capsaicin treatment using a concentration range of $0-50 \mu \mathrm{M}$ during $72 \mathrm{~h}$, in wild type ( $\mathbf{a}$ ) and TcAK overexpressing $(\bullet)$ epimastigotes. $\mathrm{IC}_{50} \mathrm{~S}$ were obtained by non-linear regression, expressed as the mean \pm standard deviation and corresponds to three independent experiments.

Figure 2. Trypanocidal activity of capsaicin on trypomastigotes. Dose-response curves of capsaicin over trypomastigotes of $T$. cruzi (A) and Vero cells (B). Treatments were performed during $24 \mathrm{~h}$ as indicated under "Materials and Methods". $\% \mathrm{OD}$ is the percentage of absorbance at $\lambda=570 \mathrm{~nm}$ of the crystal violet (vital staining) respect to the control without treatment. $I_{50}$ s were obtained by non-linear regression, expressed as the mean \pm standard deviation and corresponds to three independent experiments. 


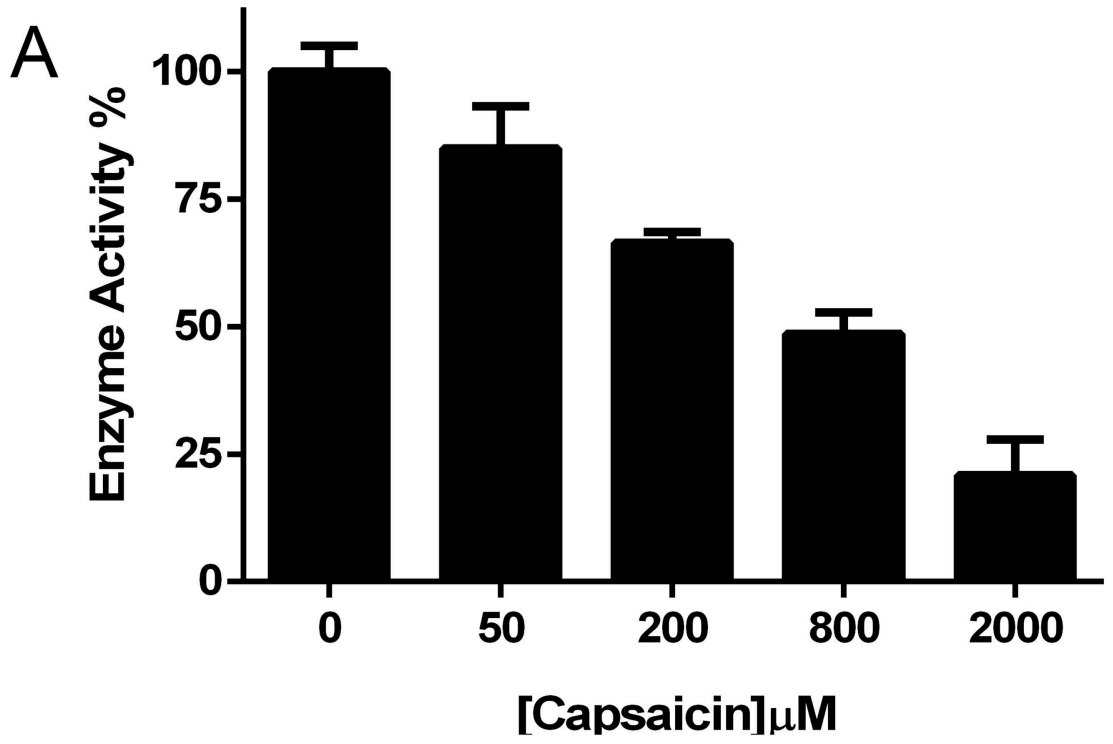

B

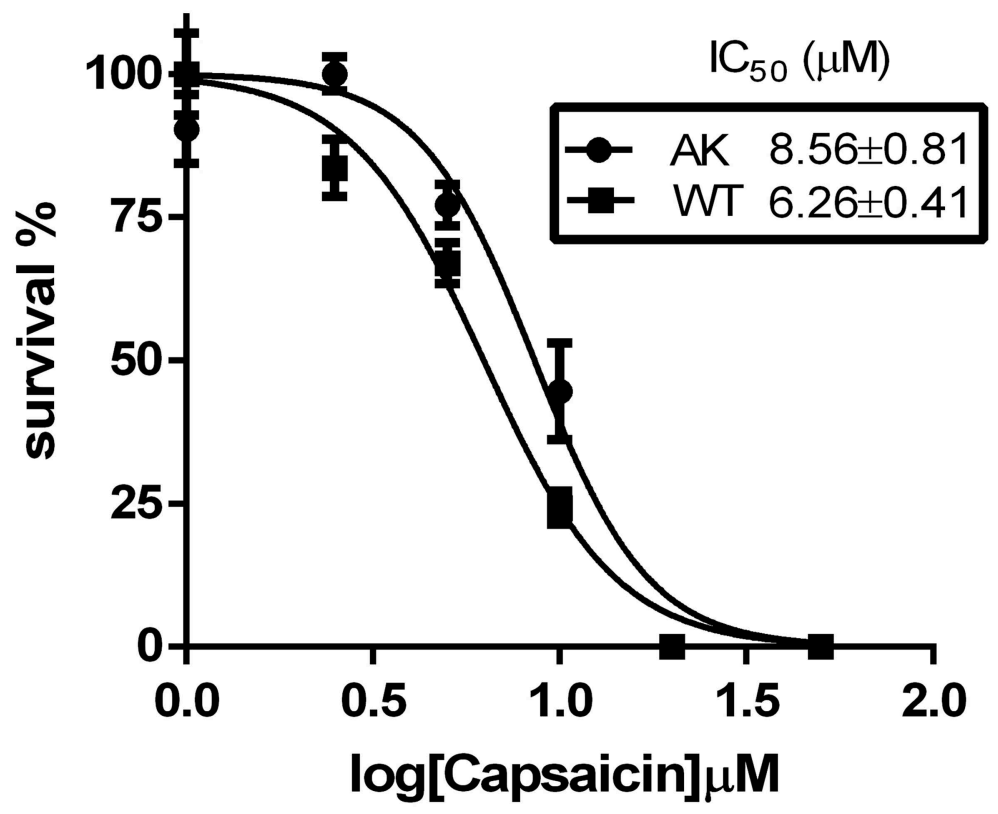



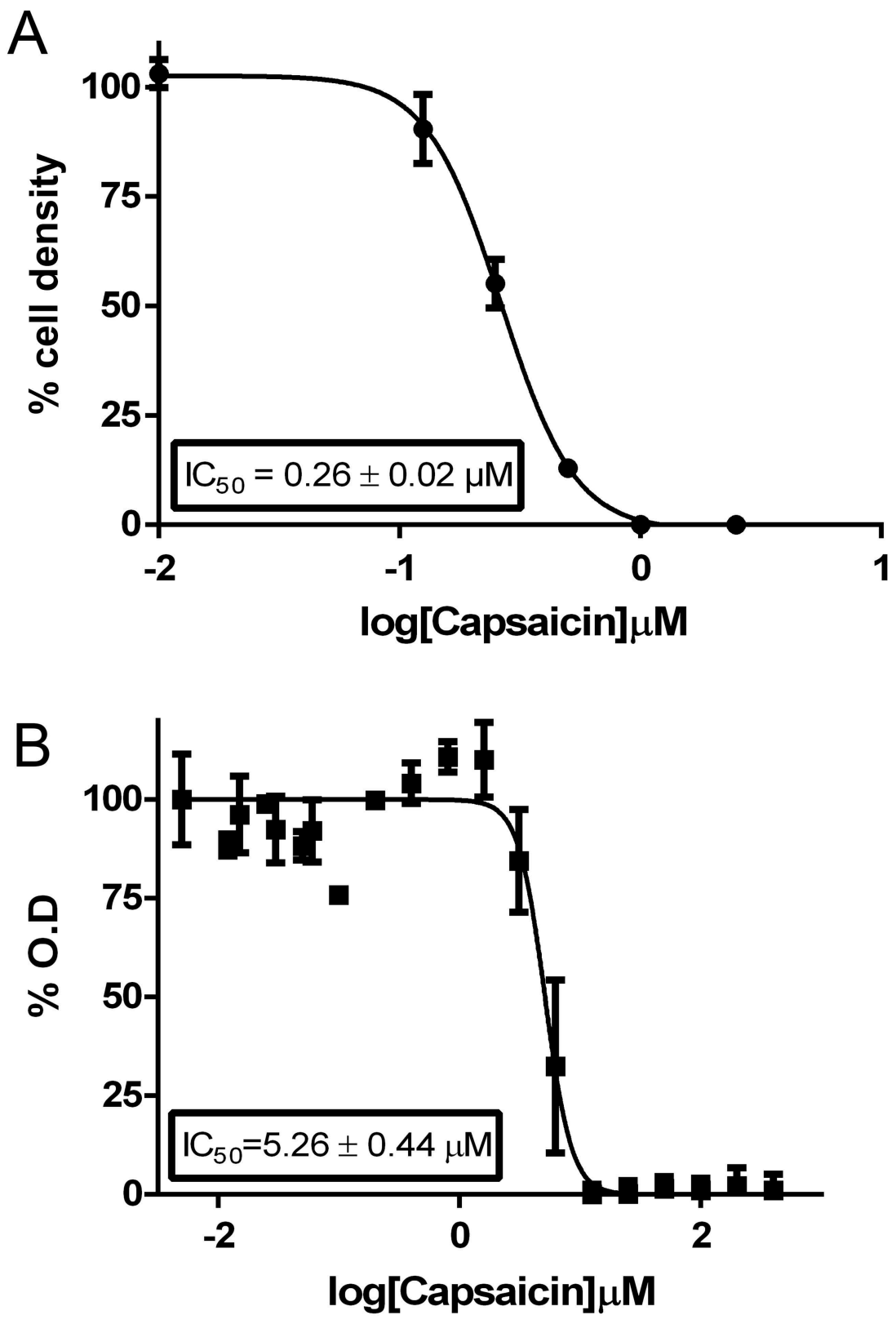